\title{
$\underline{\mathbf{P}-171}$
}

\section{Bromotyrosine-Derived Alkaloids from the Sponge Acanthodendrilla SP}

\author{
Opeyemi Olatunji* and Anuchit Plubrukarn \\ Marine Natural Product Research Unit (MNP), Department of Pharmacognosy and Pharmaceutical Botany, Faculty of \\ Pharmaceutical Sciences, Prince of Songkla University, Hat-Yai, Songkhla, 90112, Thailand; \\ E-mail: pere@fastermail.com
}

Bioassay-guided fractionation of the $\mathrm{CH}_{2} \mathrm{Cl}_{2} / \mathrm{MeOH}$ extract of the Thai marine sponge Acanthodendrilla sp. resulted in the isolation of six bromotyrosine-derived alkaloids; aerothionin (1), homoaerothionin (2), 2-hydroxy-3,5-dibromo,4methoxyphenylacetamide (3), 2,4-cyclohexadiene-1-acetamide-3,5-dibromo-1,6-dihydroxy-4-methoxy (4), 11-oxoaerothionin (5), and 11,19-dideoxyfistularin (6). The structures of the isolated compounds were identified on the basis of detailed spectroscopic analysis. The compounds were tested for the acetylcholinesterase-inhibiting activity, and 3 showed the best acetylcholinesterase-inhibiting activity $(92.0 \%$ at $0.1 \mathrm{mg} / \mathrm{mL})$.

Keywords: Acanthodendrilla sp.; bromotyrosine-derived alkaloids; acetylcholinesterase-inhibiting activity. 